\section{Advanced rectal carcinoma caused by tumor cell implantation after curative endoscopic submucosal dissection of an intramucosal rectal carcinoma}

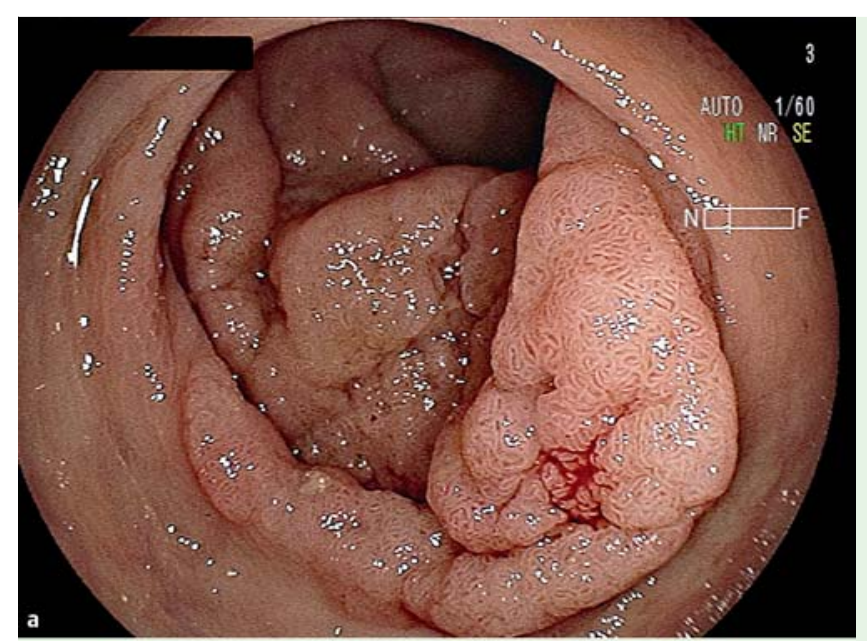

Fig. 1 Endoscopic appearance of the distal rectum showing: a a granular-type laterally spreading tumor prior to treatment; b the ulcer bed after endoscopic submucosal dissection (ESD).
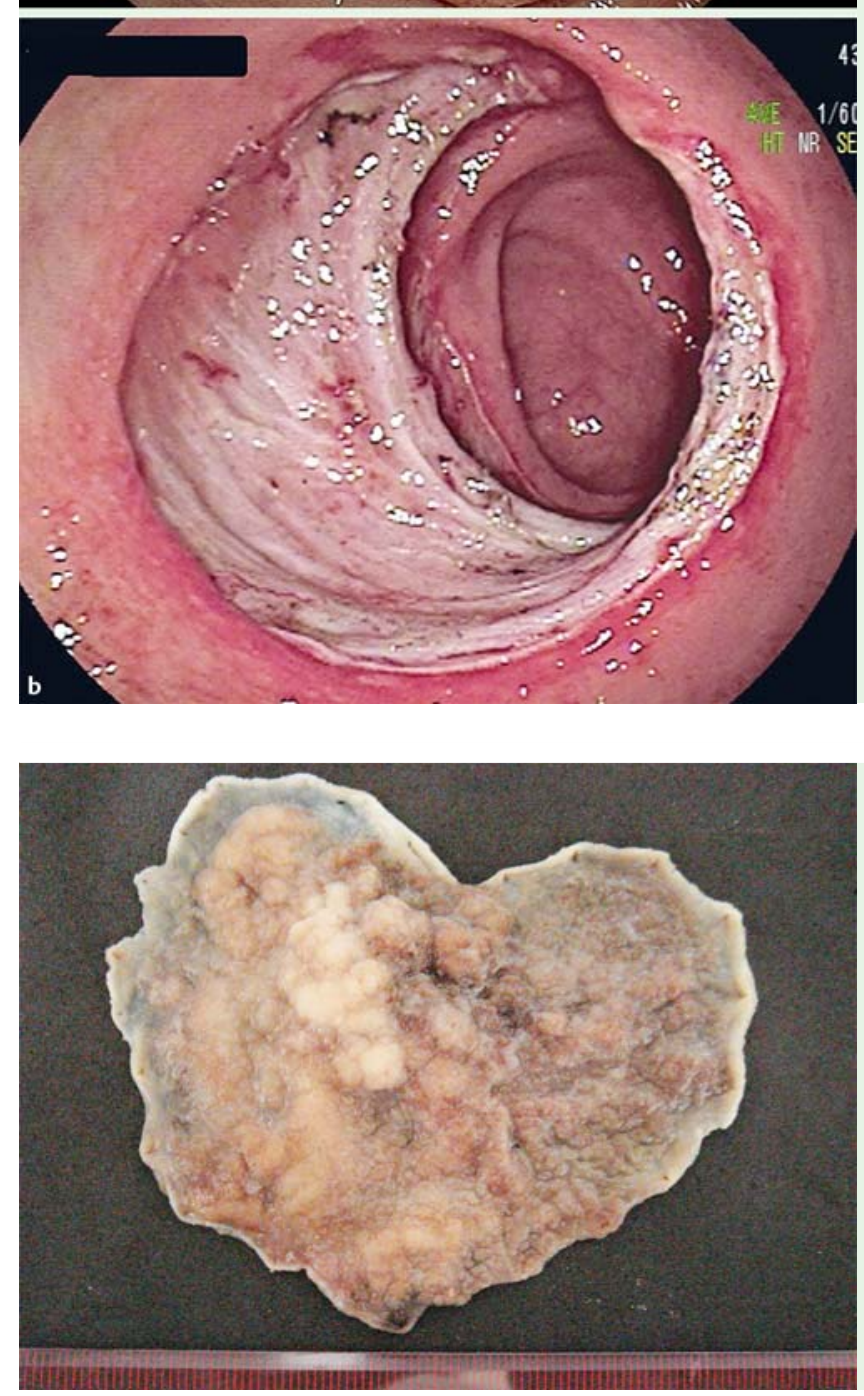

A 62-year-old man was referred for treatment of a large granular-type laterally spreading tumor in the distal rectum ( $\bullet$ Fig. 1a). We diagnosed the tumor as being an intramucosal carcinoma using magnifying endoscopy. En bloc resection was performed by endoscopic submucosal dissection (ESD) ( $\bullet$ Fig. 1 b and $\bullet$ Fig. 2).

Histopathologic examination of the resected specimen showed an intramucosal adenocarcinoma with adenomatous components and tumor-free resection margins around the entire circumference of the tumor with no evidence of lymphovascular invasion ( $\mathbf{F i g . 3 a , b}$ ). The adenocarcinoma was limited to the mucosal layer reaching to the muscularis mucosa but not invading it. The vertical resection margin was also free of cancer around the entire lesion with the thinnest and thickest tumor-free submucosal depths being $360 \mu \mathrm{m}$ and $1280 \mu \mathrm{m}$, respectively ( $\bullet$ Fig. 3 c, d). The procedure was considered to have been a curative resection (R0), and the patient was discharged without complications.

A follow-up colonoscopy performed 1 year later revealed a local recurrence at the ESD scar ( Fig.4). Surgical resection of the tumor was performed. Histopathologically, the carcinoma had invaded to the muscularis propria; however, the resected lymph nodes showed no evidence of metastasis.

Incomplete resection with residual tumor and tumor cell implantation have both been reported to be recognized causes of local recurrence after surgical resection of rectal carcinoma. Exfoliated free viable tumor cells in the remaining rectal lumen can implant at the anastomosis and on the raw surface [ 1 - 3]. In this case residual tumor was not seen near the ESD ulcer on video review. A post-ESD ulcer may, however, serve as a raw surface on which free viable tumor cells can implant. Therefore, local recurrence of the rectal carcinoma may have been caused by tumor cell implantation.

To the best of our knowledge, this is the first description of a local recurrence of early rectal carcinoma after curative ESD in the absence of the usual risk factors for local recurrence of intramucosal carcinoma after endoscopic treatment, which include positive surgical margins and piecemeal resection.

Tajika et al. [4] reported a case of tumor cell implantation from a rectosigmoid co- 


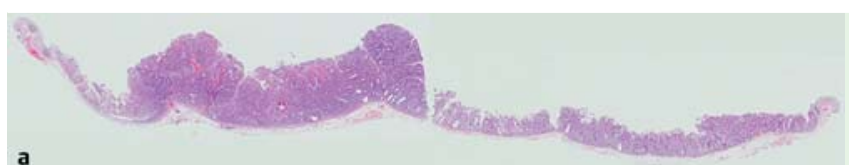

a

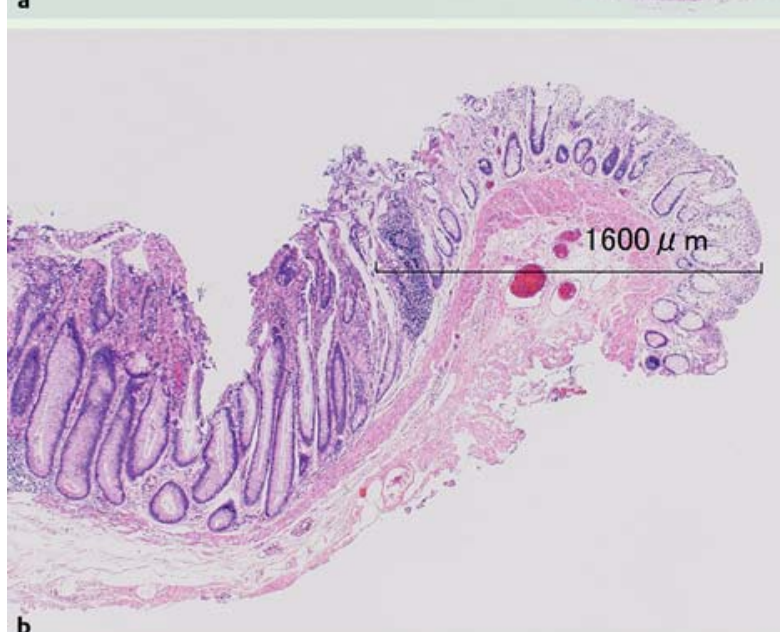

b
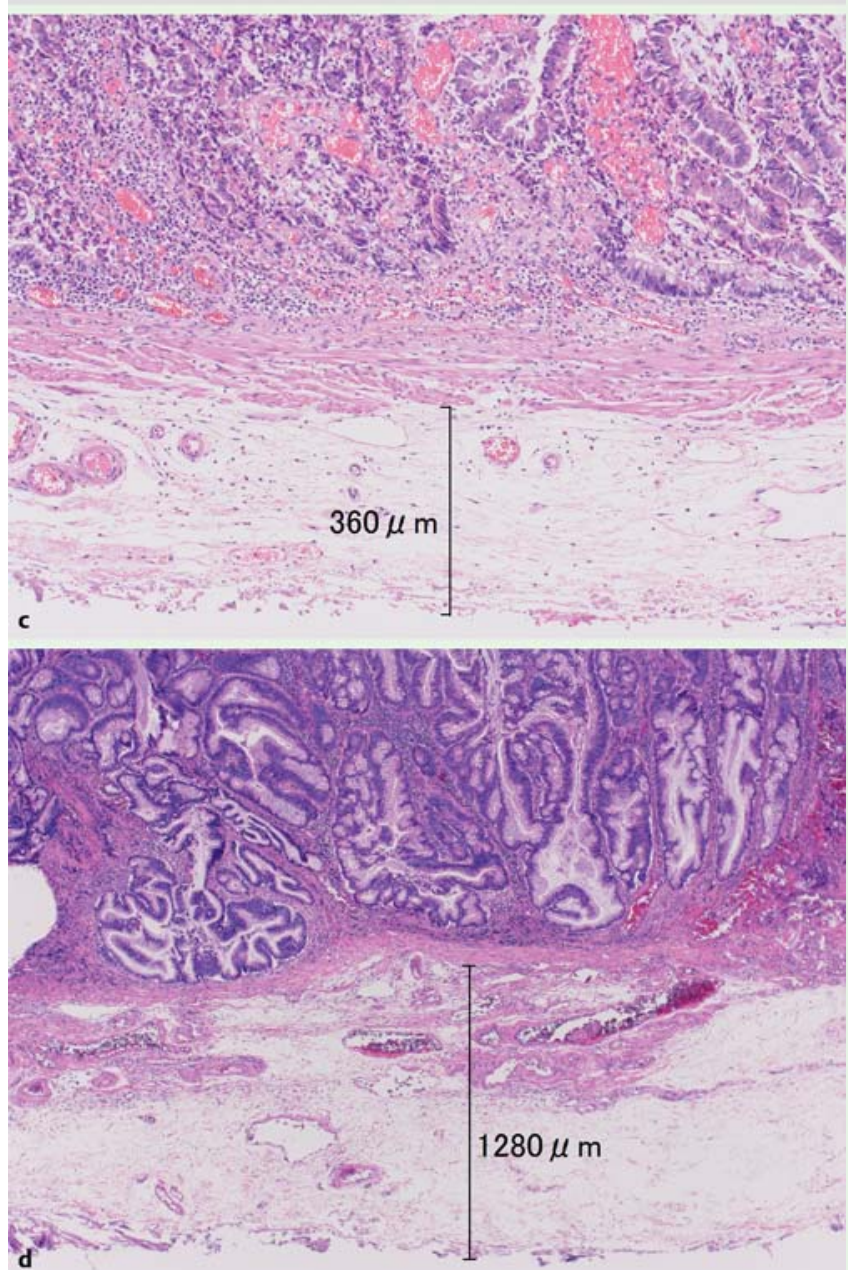

Fig. 3 Histopathologic appearance of the resected specimen stained with hematoxylin and eosin (H\&E) showing: a an intramucosal adenocarcinoma with adenomatous components in low-power view; and b the same tissue in high-power view demonstrating tumor-free resection margins without lymphovascular invasion; $\mathbf{c}$ the thinnest submucosal depth under the resected carcinoma $(360 \mu \mathrm{m})$; d the thickest submucosal depth under the resected carcinoma $(1280 \mu \mathrm{m})$. lonic cancer at the endoscopic mucosal resection (EMR) site of a synchronous rectal carcinoid. This report supports the concept of tumor cell implantation in an ESD ulcer. Endoscopists should be aware of this potential risk when performing ESD for large colorectal tumors.

Endoscopy_UCTN_Code_TTT_1AQ_2AD

Competing interests: None

\section{Hakuei Shinhata ${ }^{1}$, Hironori Yama- moto ${ }^{1}$, Keijiro Sunada', Yuji Ino', Yoshikazu Hayashi ${ }^{1}$, Hiroyuki Sato ${ }^{1}$, Yoshimasa Miura', Hirotsugu Saka- moto', Aya Kitamura', Takahito Take- zawa', Tomonori Yano', Takashi Saka- tani $^{2}$, Kentaro Sugano ${ }^{1}$}

${ }^{1}$ Department of Medicine, Division of Gastroenterology, Jichi Medical University, Tochigi, Japan

${ }^{2}$ Department of Pathology, Jichi Medical University, Tochigi, Japan

\section{Acknowledgment}

The authors wish to thank Professor Alan Lefor of the Department of Surgery at Jichi Medical University for the language editing of this manuscript.

\section{References}

1 Matsuda A, Kishi T, Musso G et al. The effect of intraoperative rectal washout on local recurrence after rectal cancer surgery: a metaanalysis. Ann Surg Oncol 2013; 20: 856 863

2 Morgan CN. Cancer of the rectum. Ann R Coll Surg Engl 1951; 9: 13-24

3 Umpleby HC, Fermor B, Symes MO et al. Viability of exfoliated colorectal carcinoma cells. Br J Surg 1984; 71: 659-663

4 Tajika M, Niwa Y, Bhatia Vet al. A first report of tumor cell implantation after EMR in a patient with rectosigmoid cancer. Gastrointest Endosc 2012; 75: 1117-1118 


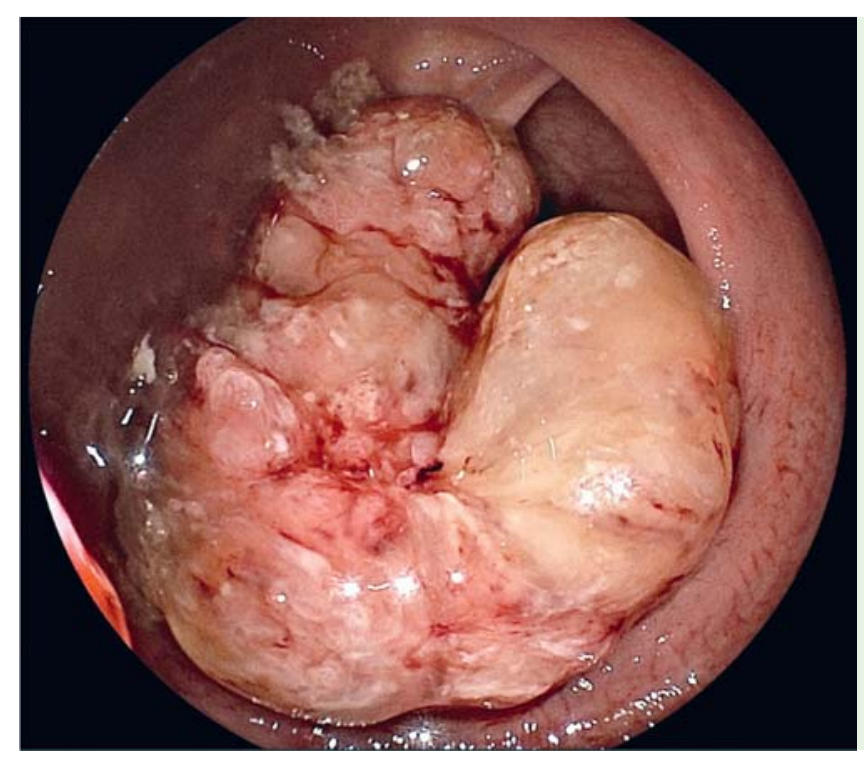

Fig. 4 Follow-up colonoscopy 13 months after the endoscopic submucosal dissection (ESD) was performed showing a recurrent rectal carcinoma at the site of the ESD scar.

\section{Bibliography}

Dol http://dx.doi.org/

10.1055/s-0034-1377211

Endoscopy 2015; 47: E192-E194

(c) Georg Thieme Verlag KG

Stuttgart · New York

ISSN 0013-726X

\section{Corresponding author}

Hironori Yamamoto, MD, PhD

Department of Medicine,

Division of Gastroenterology

Jichi Medical University

3311-1 Yakushiji

Shimotsuke

Tochigi, 329-0498

Japan

Fax: +81-285-448297

yamamoto@jichi.ac.jp 